\title{
Influence of coloring voltage on the optical performance and cycling stability of a polyaniline-indium hexacyanoferrate electrochromic system
}

\author{
Jen-Yuan Wang ${ }^{\mathrm{a}}$, Chong-Mu Yu ${ }^{\mathrm{b}}$, Shou-Chia Hwang ${ }^{\mathrm{b}}$, Kuo-Chuan $\mathrm{Ho}^{\mathrm{a}, \mathrm{c}}$, Lin-Chi Chen ${ }^{\mathrm{b}, \mathrm{d}, *}$ \\ ${ }^{a}$ Institute of Polymer Science and Engineering, National Taiwan University, Taipei 10617, Taiwan \\ ${ }^{\mathrm{b}}$ Department of Bio-Industrial Mechatronics Engineering, National Taiwan University, Taipei 10617, Taiwan \\ ${ }^{\mathrm{c}}$ Department of Chemical Engineering, National Taiwan University, Taipei 10617, Taiwan \\ ${ }^{\mathrm{d} B i o e n e r g y ~ R e s e a r c h ~ C e n t e r, ~ N a t i o n a l ~ T a i w a n ~ U n i v e r s i t y, ~ T a i p e i ~ 10617, ~ T a i w a n ~}$
}

Received 6 August 2006; received in revised form 30 November 2006; accepted 24 February 2007

Available online 29 October 2007

\begin{abstract}
An electrochromic system based on the multielectrochromic polyaniline (PANI) and pseudo-transparent indium hexacyanoferrate (InHCF) thin-film electrodes was studied in this work. In combination with a hybrid $\mathrm{H}^{+} / \mathrm{K}^{+}$-conducting solid polymer electrolyteKCl-doped poly(2-acrylamido-2-methylpropanesulfonic acid) (K-PAMPS), a precoloring-free PANI-InHCF electrochromic device (ECD) with an active area of $3 \times 3 \mathrm{~cm}^{2}$ was fabricated and exhibited yellowish-green-blue multicolor electrochromism. From in situ spectroelectrochemical experiments, we found that the performance of a PANI/K-PAMPS/InHCF ECD was significantly affected by the operating voltages, especially by the coloring voltage. Both the bleached and yellowish state of the ECD could be attained reversibly by applying a voltage ranging from +1.5 to $+1.7 \mathrm{~V}$ (InHCF vs. PANI). Different coloring voltages resulted in different optical properties and cycling stabilities, however. For instance, the device biased at $-1.6 \mathrm{~V}$ (InHCF vs. PANI) showed a deep blue color, but the optical activity decayed quickly (less than 50 cycles) when the device was switched between +1.6 and $-1.6 \mathrm{~V}$. Nevertheless, the device could be reversibly operated between +1.6 and $0 \mathrm{~V}$ for several hundred cycles, although a narrower electrochromic extent (yellowish-to-green) was observed correspondingly. The optimization of the coloring voltage is therefore of paramount importance to the PANI/K-PAMPS/ InHCF ECD.
\end{abstract}

(C) 2007 Elsevier B.V. All rights reserved.

Keywords: Coloration efficiency; Electrochromic device; Indium hexacyanoferrate; Poly(2-acrylamido-2-methylpropanesulfonic acid); Polyaniline

\section{Introduction}

Electrochromism is a phenomenon related to optical changes occurring in chemical materials by a reversible electrochemical process. The electrochromic effect results from the generation of different electronic absorption bands in the visible region, which corresponds to the changes between at least two redox states [1,2]. The color change of the electrochromic materials typically ranges from a transparent (bleached) state to a colored state, or

\footnotetext{
*Corresponding author. Department of Bio-Industrial Mechatronics Engineering, National Taiwan University, Taipei 10617, Taiwan.

Tel.: + 886233665343 ; fax: +886223627620 .

E-mail address: chenlinchi@ntu.edu.tw (L.-C. Chen).
}

between two colored states at varying voltages. In the case of materials with more than two redox states, the materials may exhibit several colored states and be termed polyelectrochromic. Electrochromic materials have been attracting much interest for several decades, as they have several important applications, such as electrochromic windows [3,4], rear-view mirrors [5], electrochromic displays [6], and electronic paper or electrochromic painting [7].

Indium hexacyanoferrate (InHCF) is one of the polynuclear transition metal hexacyanometallates, which can be expressed as a general formula $M_{k}{ }^{A}\left[M^{B}(\mathrm{CN})_{6}\right]_{l}$, where $M^{A}$ and $M^{B}$ are transition metals with different oxidation numbers. The first report regarding the electrochromism of InHCF was published by Jin et al. [8], and this material exhibited light electrochromism which ranged in color from 
yellowish to colorless. With this feature, InHCF can potentially be considered a pseudo-transparent electrode for the application in electrochromic systems. Also, the redox reaction of InHCF is accompanied by the insertion and extraction of monovalent cations, the most appropriate for this thin film being $\mathrm{K}^{+}$[8-10].

In recent years, many studies have focused on the use of conducting polymers in electrochromism for their vivid color changes. Polyaniline (PANI) - which is one of the conducting polymers subject to intensive investigationexhibits multicolor electrochromism during the electrochemical doping process. The main redox states of PANI are the fully reduced leucoemeraldine form, the $50 \%$ oxidized emeraldine form, and the fully oxidized pernigraniline form. A PANI thin film therefore exhibits yellow for the leucoemeraldine base (LB) state, green for emeraldine salt (ES), blue for emeraldine base (EB), and black for pernigraniline salt (PS). Also, it was reported that PANI could exhibit better reversibility in the yellow-green transition [11]. There are many applications of PANI, such as electrochromic displays [12], batteries [13], and sensors [14].

For assembling InHCF and PANI thin films into a new electrochromic device, employing the $\mathrm{KCl}$-doped poly (2-acrylamido-2-methylpropanesulfonic acid) (K-PAMPS) as the electrolyte layer was considered, since it would provide both the protons and the $\mathrm{K}^{+}$ions required in this electrochromic system. The K-PAMPS electrolyte was modified from poly(2-acrylamido-2-methylpropanesulfonic acid) (PAMPS) - a polyelectrolyte of $\mathrm{H}^{+}$[15]. The evidence that the K-PAMPS electrolyte accommodates conduction and insertion of both $\mathrm{K}^{+}$and $\mathrm{H}^{+}$ions has been demonstrated and discussed thoroughly in our earlier papers [16-18]. In this study, we first investigated the electrochemical and optical properties of PANI and InHCF in conjunction with K-PAMPS gel polymer electrolyte. The PANI/K-PAMPS/InHCF ECD was then assembled in a sandwich configuration. Since the dominant electrochromic contribution of the present system is from PANI, both optical and electrochemical properties of the device might be significantly affected by coloring voltage, which determines the redox states of PANI. Consequently, we aimed to discover the influence of coloring voltage on this ECD's optical performance and cycling stability. Also, the feasibility of the PANI/K-PAMPS/InHCF ECD will be discussed in this paper.

\section{Experimental}

\subsection{Chemicals}

All chemicals were ACS reagent grade and used without further purification. Potassium chloride $(\mathrm{KCl})$, potassium ferricyanide $\left(\mathrm{K}_{3} \mathrm{Fe}(\mathrm{CN})_{6}\right)$, indium chloride $\left(\mathrm{InCl}_{3}\right)$, tetra (ethylene glycol diacrylate), and 2-acrylamido-2-methyl-1propansulfonic acid (AMPS) were purchased from Aldrich. Benzoin methyl ether (BME) and hydrochloric acid ( $\mathrm{HCl})$ were purchased from Fluka. Aniline (99.5\%) was purchased from Merck. All aqueous solutions were made with deionized water (DIW) of a resistivity of about 18.2 $\mathrm{M} \Omega-\mathrm{cm}$. Experiments were all done at room temperature and in air.

\subsection{Substrates}

Optically transparent Sn-doped indium oxide $\left(\operatorname{In}_{2} \mathrm{O}_{3}: \mathrm{Sn}\right.$, or ITO) glass substrates $\left(R_{\mathrm{sh}}=20 \Omega / \square\right.$, Ritdisplay Corporation, Hsinchu, Taiwan) with dimensions of $4.0 \times 5.0 \times 0.1 \mathrm{~cm}^{3}$ were used as the conducting substrates for the deposition of electrochromic thin films. Prior to their use, the ITO substrates were cleaned ultrasonically in a $0.1 \mathrm{M} \mathrm{HCl}$ solution for $2 \mathrm{~min}$ and then in DIW for another $2 \mathrm{~min}$. The substrates were dried in air, and then epoxy tapes (3 M Company) were attached to them to obtain a centralized electroactive area of $3.0 \times 3.0 \mathrm{~cm}^{2}$. Copper tape ( $3 \mathrm{M}$ Company, $3.0 \times 0.5 \mathrm{~cm}$ ) was applied to one side of the ITO as the bus bar.

\subsection{Preparation of PANI films}

A potentiostat/galvanostat (Autolab model PGSTAT30) was used for the electrodeposition of both PANI and InHCF thin films and also used for all other electrochemical experiments such as cyclic voltammetry (CV) analyses.

The PANI thin films were electropolymerized in an aniline $\left(\mathrm{C}_{6} \mathrm{H}_{5} \mathrm{NH}_{2}\right)$ solution. The solution was composed of $1.0 \mathrm{M}$ aniline, $2.0 \mathrm{M} \mathrm{HCl}$, and deionized water. In preparing PANI thin films, a constant potential of $0.8 \mathrm{~V}$ (vs. $\mathrm{Ag} / \mathrm{AgCl} / \mathrm{sat}$ 'd $\mathrm{KCl}$ ) was applied to the ITO glass substrates for $120 \mathrm{~s}$. PANI thin films were then washed with $0.1 \mathrm{M} \mathrm{HCl}$ - to remove the residual deposition solutions, dried under $\mathrm{N}_{2}$, then stored in air. During the electropolymerization, the ITO glass substrate served as a working electrode, a platinum sheet $\left(4.0 \times 1.0 \mathrm{~cm}^{2}\right)$ as a counter electrode, and a homemade $\mathrm{Ag} / \mathrm{AgCl} / \mathrm{sat}$ 'd $\mathrm{KCl}$ as a reference electrode. All applied potentials on PANI and InHCF thin-film electrodes reported below are relative to a $\mathrm{Ag} / \mathrm{AgCl} /$ sat'd $\mathrm{KCl}$ reference electrode unless otherwise indicated. The average thickness of the PANI thin films was $100 \mathrm{~nm}$, as measured with a profilometer (Sloan, Dektak 3).

\subsection{Preparation of InHCF films}

For the electrodeposition of InHCF thin films, the deposition bath contained $10 \mathrm{mM} \mathrm{K} \mathrm{K}_{3} \mathrm{Fe}(\mathrm{CN})_{6}, 10 \mathrm{mM}$ $\mathrm{InCl}_{3}, 0.1 \mathrm{M} \mathrm{KCl}$, and $0.1 \mathrm{M} \mathrm{HCl}$. During the plating process, a potential scanned back and forth - between 0.2 and $1.3 \mathrm{~V}$ (vs. $\mathrm{Ag} / \mathrm{AgCl} / \mathrm{sat}^{\prime} \mathrm{KCl}$ ) at a rate of $50 \mathrm{mV} / \mathrm{s}-$ was applied onto the ITO substrate for 30 cycles. After electrodeposition, the InHCF thin films were washed with DIW and stored in air. When another electrochromic electrode, such as $\mathrm{WO}_{3}$, is used to assemble with anodically 
coloring PANI, a pre-coloring step is usually required to reduce the electrode to its colored state after deposition or storage in air [19]. However, in this electrochromic system, InHCF is used as a pseudo-transparent counter electrode, so it is pre-coloring free for ECD assembly. Moreover, elimination of the pre-coloring step can significantly improve the at-rest instability problem of an ECD [18].

\subsection{Preparation of K-PAMPS gel electrolytes}

The K-PAMPS electrolytes were prepared by UV polymerization, and this procedure was modified from those reported by Giglia [20]. The AMPS monomer solution for the formation of K-PAMPS was prepared as follows: $9.8 \mathrm{~g}$ of AMPS monomer was first dissolved into a $10 \mathrm{ml}, 0.1 \mathrm{M} \mathrm{KCl}$ solution (to provide potassium ions). Next, $0.3 \mathrm{ml}$ of tetra(ethylene glycol diacrylate) (TEGDA) was dropped into this solution as a cross-linking agent. The solution was stirred for $15 \mathrm{~min}$ at room temperature. Next, $0.01 \mathrm{~g}$ of benzoin methyl ether (BME) was added as the initiator, and the resultant AMPS monomer solution was stirred for another $15 \mathrm{~min}$ before UV polymerization. During polymerization, K-PAMPS were formed upon InHCF thin film with the dimensions of $3.0 \times 3.0 \mathrm{~cm}^{2}$ under an exposure of ca. $675 \mu \mathrm{W} / \mathrm{cm}^{2}$ UV irradiation for three minutes. According to our earlier paper, the ionic conductivity of the K-PAMPS electrolyte was ca. $0.13 \pm 0.01 \Omega^{-1} \mathrm{~cm}^{-1}[17]$.

\subsection{Assembly of the PANI-InHCF ECD}

Prior to assembling the device, PANI was cycled several times in a $0.1 \mathrm{M} \mathrm{HCl}$ by the $\mathrm{CV}$ method for activating the thin film. The K-PAMPS gel electrolyte was formed on the active area of the InHCF thin film by in situ UV polymerization. K-PAMPS gel electrolyte was sandwiched in between PANI and InHCF modified electrodes, and the cell gap was set at $280 \mu \mathrm{m}$ with a spacer tape. This device was finally sealed with Torr Seal ${ }^{\circledR}$ (Varian, \#9530001), and the active area for each ECD was $3.0 \times 3.0 \mathrm{~cm}^{2}$.

\subsection{Characterization of films and ECD: electrochemical and spectroscopic analyses}

The in situ spectroelectrochemical measurements were carried out by a UV-visible spectrophotometer (Shimadzu model UV-1601PC). The PANI and InHCF electrodes were analyzed by the three-electrode system in contact with the K-PAMPS gel electrolyte. The two-electrode system was used to characterize the PANI-InHCF ECD. For the three-electrode analyses, the counter and reference electrodes were platinum plate and $\mathrm{AgCl}$-coated silver wire (denoted as $\mathrm{Ag} / \mathrm{Ag}^{+}$), respectively. For the two-electrode analyses, the positive electrode was set as InHCF, and the negative one was PANI. The equilibrium transmittance spectra of the ECD at different applied voltages were collected with the potentiostat/galvanostat and spectrophotometer during the in situ measurements.

\section{Results and discussion}

\subsection{Studies of PANI and InHCF thin-film electrodes}

\subsubsection{Cyclic voltammetry and electrochemical properties}

The full scan-range CV curves for PANI and InHCF obtained in K-PAMPS gel electrolyte are shown in Figs. 1(a) and (b). In Fig. 1(a), the PANI thin film electrode was scanned between -0.7 and $0.7 \mathrm{~V}$ at a scan rate of $100 \mathrm{mV} / \mathrm{s}$, and there exists three couples of redox waves. The first anodic peak at ca. $-0.25 \mathrm{~V}\left(\mathrm{~A}^{\mathrm{I}}\right)$ corresponds to the reaction between LB and ES, and this

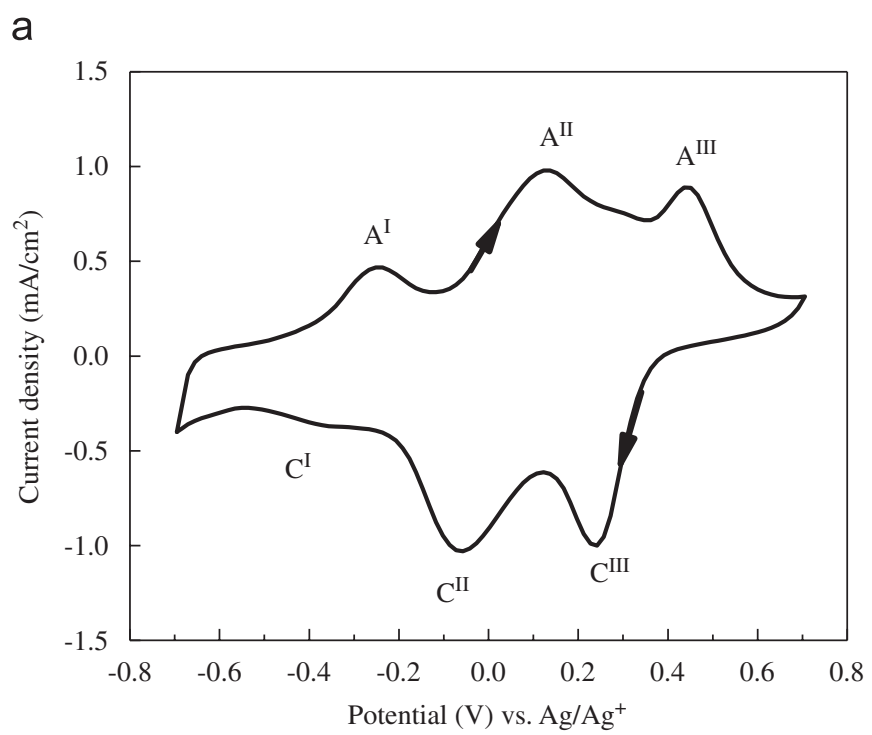

b

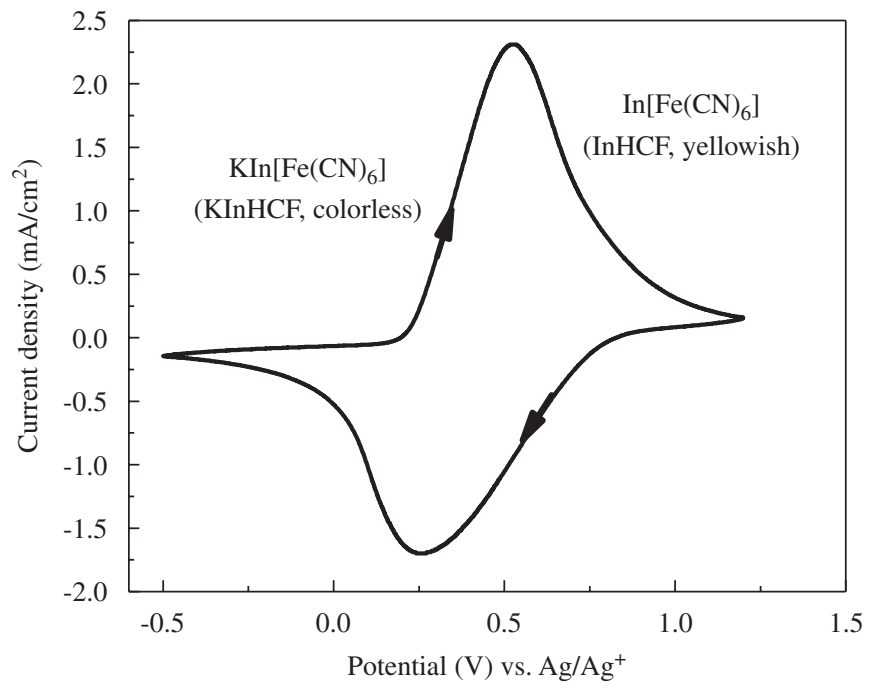

Fig. 1. Typical full-range CVs for (a) PANI thin film modified ITO electrode scanned from -0.7 to $0.7 \mathrm{~V}$ at a scan rate of $100 \mathrm{mV} / \mathrm{s}$ (vs. $\mathrm{Ag} /$ $\mathrm{Ag}^{+}$) and (b) InHCF thin film modified ITO electrode scanned from -0.5 to $1.2 \mathrm{~V}$ (vs. $\mathrm{Ag} / \mathrm{Ag}^{+}$) at a scan rate of $50 \mathrm{mV} / \mathrm{s}$ in contact with the K-PAMPS solid electrolyte, respectively. 
can be expressed as follows:

$$
\begin{aligned}
& \mathrm{PANI}+n \mathrm{Cl}^{-} \\
& (\mathrm{LB}, \text { yellow })
\end{aligned} \underset{(\mathrm{ES}, \text { green })}{\left(\mathrm{PANI}^{n+}\right)\left(\mathrm{Cl}^{-}\right)_{n}+\mathrm{e}^{-} .}
$$

The second anodic peak at ca. $0.1 \mathrm{~V}\left(\mathrm{~A}^{\mathrm{II}}\right)$ probably relates to a side reaction which leads to a partially reversible reaction of PANI film between the ES and EB form [21], as can be illustrated below:

$$
\begin{aligned}
& \mathrm{ES} \\
& \text { (green) }
\end{aligned} \underset{\text { (blue) }}{\mathrm{EB}+n \mathrm{Cl}^{-}+n \mathrm{H}^{+}} \text {. }
$$

The third anodic peak at ca. $0.45 \mathrm{~V}\left(\mathrm{~A}^{\mathrm{III}}\right)$ corresponds to the reaction between EB and the PS, as represented by the following equation:

$$
\begin{aligned}
\mathrm{EB}+m \mathrm{Cl}^{-} \leftrightharpoons & \left(\mathrm{EB}^{m+}\right)\left(\mathrm{Cl}^{-}\right)+m \mathrm{e}^{-} \\
\text {(blue) } & (\mathrm{PS}, \text { black })
\end{aligned} .
$$

To attain reversible PANI electrochromism, the operating potentials beyond the ES/EB redox range are not suitable.

In Fig. 1(b), the InHCF thin-film electrode was cycled between -0.5 and $1.2 \mathrm{~V}$ at a scan rate of $50 \mathrm{mV} / \mathrm{s}$, and there is only one couple of redox peaks around ca. $0.4 \mathrm{~V}$, which corresponds to the reaction between $\operatorname{In}\left[\mathrm{Fe}(\mathrm{CN})_{6}\right]$ (InHCF) and $\mathrm{KIn}\left[\mathrm{Fe}(\mathrm{CN})_{6}\right](\mathrm{KInHCF})$. The redox reaction of an InHCF thin film in the presence of $\mathrm{K}^{+}$ions can be described as follows [16-18]:

$$
\begin{array}{lll}
\mathrm{In}\left[\mathrm{Fe}(\mathrm{CN})_{6}\right]+\mathrm{K}^{+}+\mathrm{e}^{-} & \leftrightharpoons \\
(\mathrm{InHCF}, \text { yellowish }) & \mathrm{KIn}\left[\mathrm{Fe}(\mathrm{CN})_{6}\right] \\
(\mathrm{KInHCF}, \text { colorless })
\end{array} .
$$

The cathodic peak of InHCF is smaller and flatter than that of the anodic one, the implication being that InHCF shows a rather rapid anodic process in K-PAMPS, which is consistent with our earlier study [16-18].

\subsubsection{Transmittance spectra and coloration efficiency}

The equilibrated transmittance spectra-in the visible region $(400-800 \mathrm{~nm})$ for the PANI thin-film electrode measured at different applied potentials from -0.5 to $0.5 \mathrm{~V}$ (vs. $\mathrm{Ag} / \mathrm{Ag}^{+}$) with a decrement of $0.1 \mathrm{~V}$ in K-PAMPS gel electrolyte - are shown in Fig. 2. By applying more positive potentials, the transmittance in the range between 450 and $800 \mathrm{~nm}$ decreased, while the values increased between 400 and $450 \mathrm{~nm}$. When the potential reaches $0.4 \mathrm{~V}$ and beyond, the transmittance spectra rise significantly. Presumably, this result responds to the change between EB and PS.

The relationship between the optical density change $(\triangle \mathrm{OD})$ and the reacted charge density of a PANI thin film is shown in Fig. 3, which was measured at different applied potentials, beginning with $-0.6 \mathrm{~V}$ (bleached state). The data points can be categorized into two regions, corresponding to two electrochromic reactions of PANI. One is between LB and ES (Eq. (1)), with a coloration efficiency $(\eta)$ of $9.6 \mathrm{~cm}^{2} \mathrm{C}^{-1}$; the other is between ES and EB (Eq. (2)), with a $\eta$ value of $219.1 \mathrm{~cm}^{2} \mathrm{C}^{-1}$ in this region.

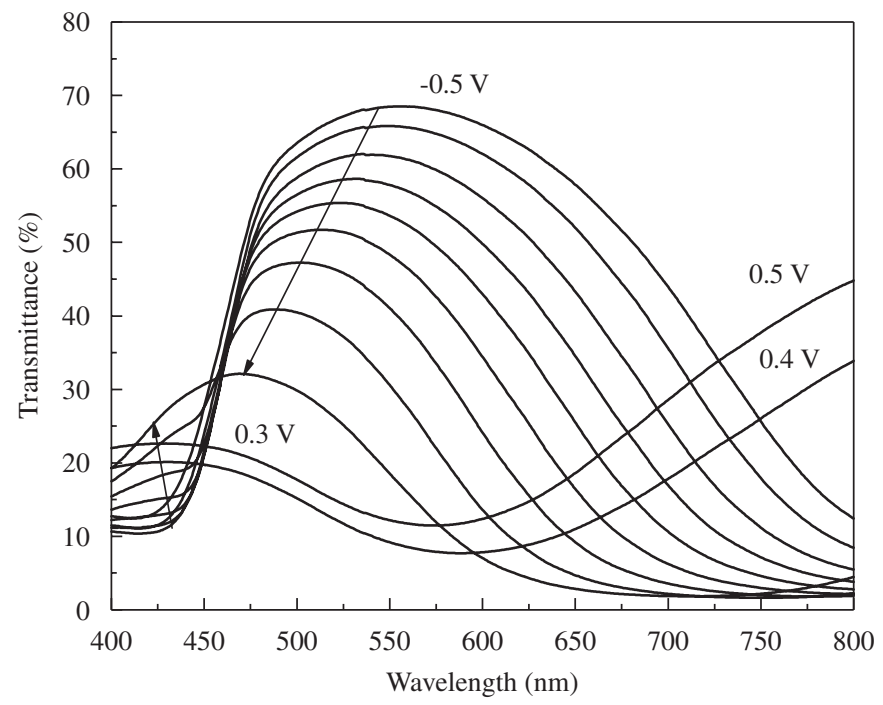

Fig. 2. In situ equilibrium transmittance spectra of a PANI thin film modified ITO electrode measured in contact with the K-PAMPS solid electrolyte at different applied potentials, stepping from -0.5 to $0.5 \mathrm{~V}$ with a $0.1 \mathrm{~V}$ increment.

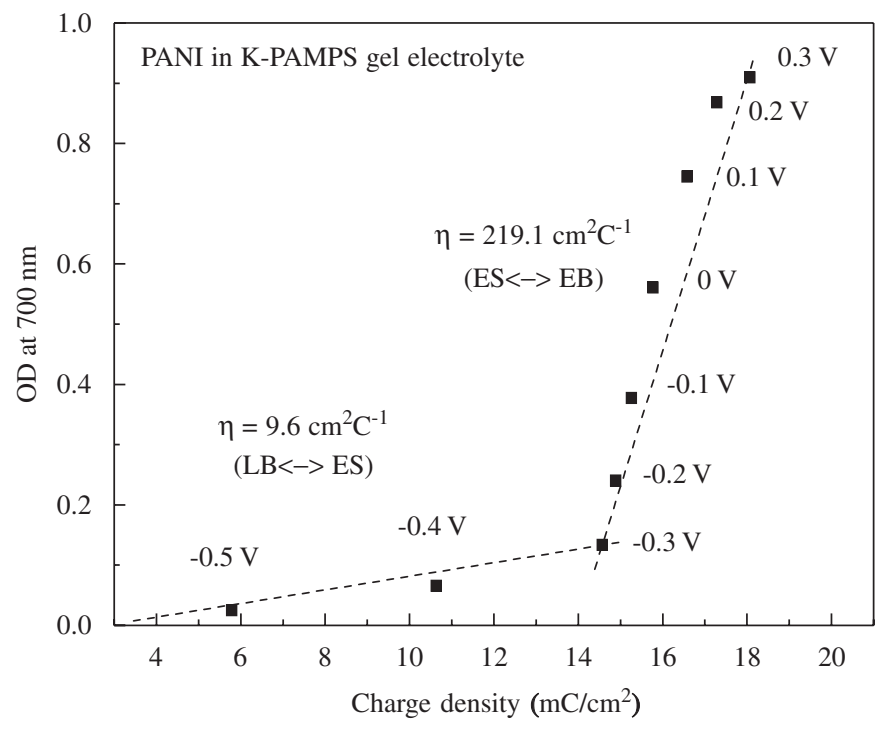

Fig. 3. The optical density change ( $\triangle \mathrm{OD}$ ) of the PANI thin-film electrode at $700 \mathrm{~nm}$ as a function of reacted charge density equilibrated at different applied potentials. The reference state was set at $-0.6 \mathrm{~V}$.

\subsection{Performance of PANI/K-PAMPS/InHCF ECD}

\subsubsection{Cyclic voltammetry analysis}

According to Eqs. (1) and (4), the overall reaction in the complementary ECD assembled with both PANI and InHCF thin-film electrodes and an ionically conducting polymer electrolyte, K-PAMPS, is given as follows:

$\begin{array}{lll}\mathrm{LB}+n \mathrm{In}\left[\mathrm{Fe}(\mathrm{CN})_{6}\right]+n \mathrm{~K}^{+}+n \mathrm{Cl} & \leftrightharpoons & \mathrm{ES}+n \mathrm{KIn}\left[\mathrm{Fe}(\mathrm{CN})_{6}\right] \\ \text { (Bleached state, yellowish) } & \text { (Darkened state, green) }\end{array}$. 
The operating voltages for this device corresponding to the bleached and colored states can be estimated as follows:

$V^{\text {colored }}=E_{\mathrm{KInHCF}}-E_{\mathrm{PANI}(\mathrm{PS})}=-0.5-0.7=-1.2 \mathrm{~V}$,

$V^{\text {bleached }}=E_{\mathrm{InHCF}}-E_{\mathrm{PANI}(\mathrm{LB})}=1.2-(-0.7)=1.9 \mathrm{~V}$,

where $E_{\mathrm{PANI}(\mathrm{PS})}, E_{\mathrm{PANI}(\mathrm{LB})}, E_{\mathrm{KInHCF}}$, and $E_{\mathrm{InHCF}}$ were estimated from the scanning ranges in $\mathrm{CVs}$ of PANI (Fig. 1(a)) and InHCF (Fig. 1(b)). The most suitable operating condition will be discussed later.

The typical CV responses of the PANI/K-PAMPS/ InHCF ECD are shown in Fig. 4. The two-electrode CVs were cycled between -2.5 and $1.6 \mathrm{~V}$ at a scan rate of $50 \mathrm{mV} / \mathrm{s}$. The cell voltage recorded is the potential difference of InHCF against PANI. Two couples of redox waves can be observed here. The oxidation peak II occurred at $-0.9 \mathrm{~V}$ and might correspond to the partially reversible switching between EB and ES of PANI [17]. In comparison with the $\mathrm{CV}$ of InHCF, the redox peaks III at ca. $0.7 \mathrm{~V}$ can be related to the characteristic peak of InHCF, as shown in Fig. 1(a). After several cycles of potential scanning, the activity of the ECD degraded rapidly. The dashed line in Fig. 4 shows the CV at tenth cycle. The irreversible side reaction of the PANI thin film occurs when operating at a wide voltage range. To obtain optimal cell performance, it is important to find a balance between the coloring voltage and the cycling stability.

\subsubsection{Transmittance spectra and coloration efficiency of the} device

Fig. 5 gives the equilibrated transmittance spectra (from 400 to $800 \mathrm{~nm}$ ) of the PANI/K-PAMPS/InHCF ECD recorded at different cell voltages $\left(E_{\text {InHCF }}\right.$ vs. PANI $)$.

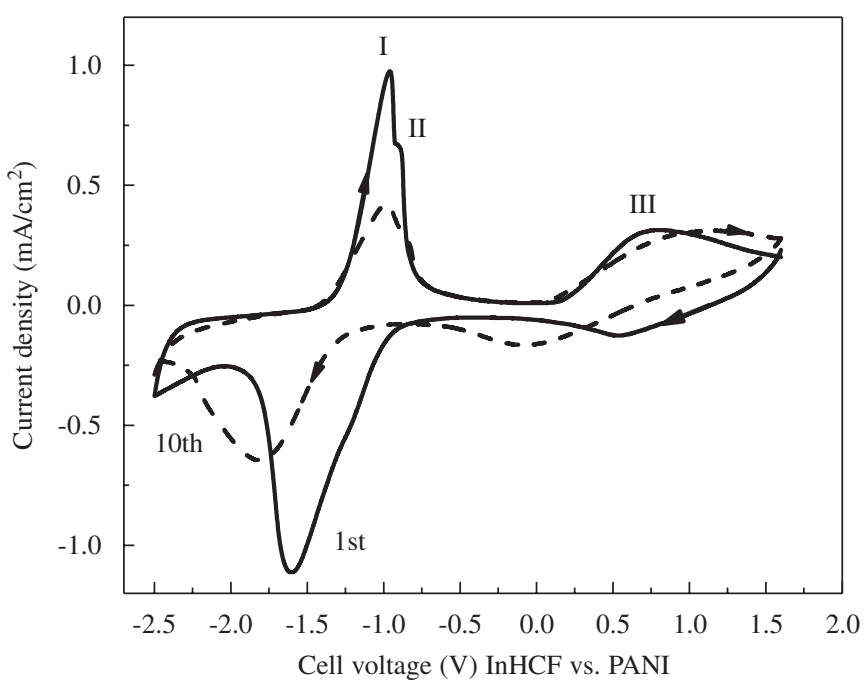

Fig. 4. Cyclic voltammograms for the PANI/K-PAMPS/InHCF ECD scanned back and forth between -2.5 and $1.6 \mathrm{~V}$ (InHCF vs. PANI) at a scan rate of $50 \mathrm{mV} / \mathrm{s}$.

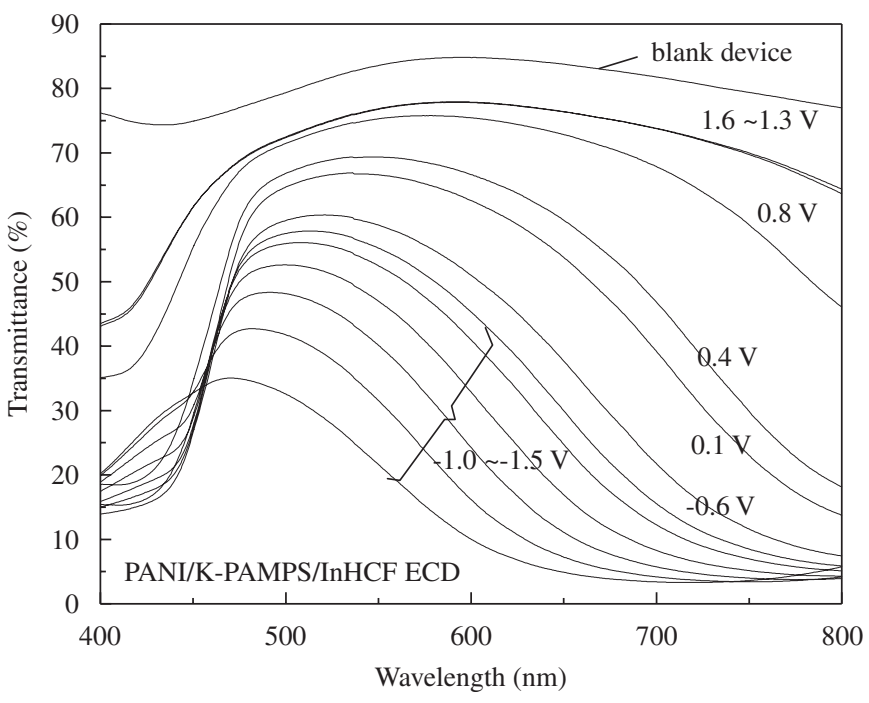

Fig. 5. In situ equilibrium transmittance spectra of the PANI/K-PAMPS InHCF ECD at different applied voltages stepping from -1.6 to $-1.5 \mathrm{~V}$ (InHCF vs. PANI) with a $0.1 \mathrm{~V}$ decrement.

The curve on the top-ranging from $75 \%$ to $85 \%$ - was the result of a blank device (assembled with two ITO glasses sandwiching the K-PAMPS electrolyte) which provided reference information. The transmittance variation attributed to the change in the operating voltage in the range between 0.4 to $-1.5 \mathrm{~V}$ (InHCF vs. PANI) is similar to that of a single PANI film as shown in Fig. 2. This confirms that the dominant electrochromic contribution for this system is from PANI. For the ECD operated between 1.3 and $1.6 \mathrm{~V}$, the transmittance did not change much and thus $1.5 \mathrm{~V}$ was chosen as the bleaching voltage for the present system. And it can be concluded from Fig. 5 that the key factor to achieving larger transmittance attenuation is the coloring voltage. In addition, it can be found that the device shows the widest capacity of optical modulation at $700 \mathrm{~nm}$.

The relationship between the change in optical density $(\triangle \mathrm{OD})$ at $700 \mathrm{~nm}$ and reacted charge density for the PANI/K-PAMPS/InHCF ECD is shown in Fig. 6. The reference state was set at $1.5 \mathrm{~V}$, and the device was then switched to different operating voltages from 1.5 to $-1.4 \mathrm{~V}$ by a decrement of $0.1 \mathrm{~V}$. The equivalent coloration efficiency was estimated to be ca. $95.2 \mathrm{~cm}^{2} \mathrm{C}^{-1}$ according to the slope fitting for the data in the range between 1.5 and $-1.5 \mathrm{~V}$.

\subsubsection{The effect of coloring voltage on the transmittance response and cycling stability}

Fig. 7 compares transmittance responses of the PANI/ K-PAMPS/InHCF ECD operated under the following conditions: bleached at $1.5 \mathrm{~V}$ for $200 \mathrm{~s}$, and colored at different coloring voltages for another 200 s. In Fig. 7(a), the coloring voltage was set at $-0.8 \mathrm{~V}$, and the device did not darken completely at the end of the coloring process. Presumably, this could be attributed to the insufficient 


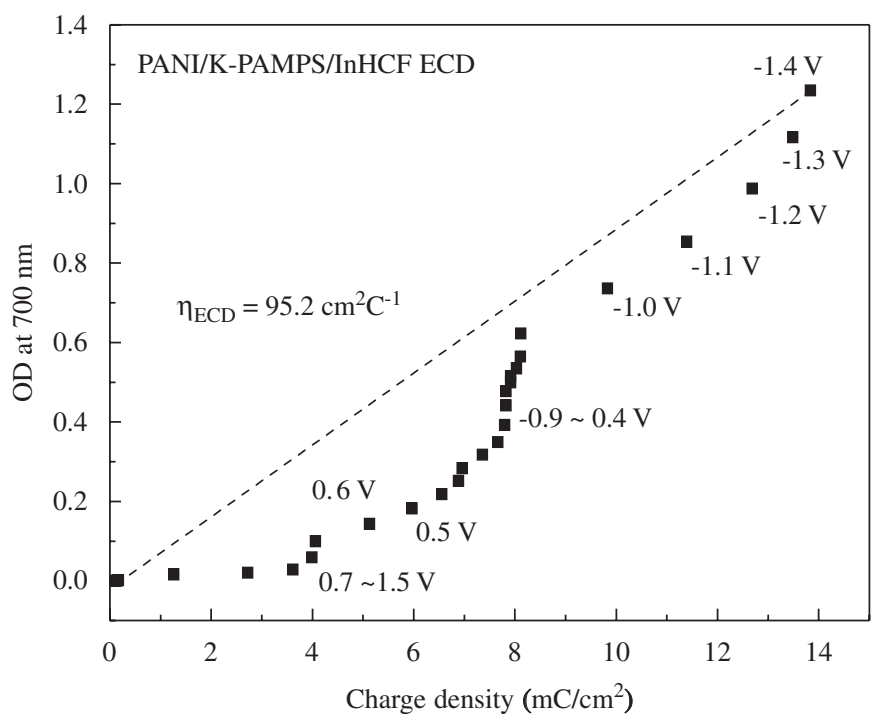

Fig. 6. The optical density change $(\triangle \mathrm{OD})$ of the PANI/K-PAMPS/ InHCF ECD at $700 \mathrm{~nm}$ as a function of reacted charge density measured at different applied voltages (InHCF vs. PANI). The reference state is set at $1.5 \mathrm{~V}$.

driving force for coloration. When more negative cell voltages were applied, such as -1.0 and $-1.2 \mathrm{~V}$ (Fig. 7(b) and (c)), the transmittance responses were more complete, and the transmittance attenuation $(\Delta T)$ increased from $45 \%(-0.8 \mathrm{~V})$ to $60 \%(-1.2 \mathrm{~V})$. Taking both transmittance attenuation and response time into consideration, we chose $15 \mathrm{~s}$ as the step time as well as the sampling time for both the coloring and bleaching processes.

The cycling stability data for PANI/K-PAMPS/InHCF ECDs operated at different coloring voltages (ranging between -0.8 and $-1.5 \mathrm{~V}$ ) are shown in Fig. 8. In Figs. 8(a)-(d), it can be seen that the device is able to be colored reversibly for at least 100 cycles in the range of -0.8 and $-1.2 \mathrm{~V}$. Moreover, the optical performance $(\Delta T)$ can be greatly enhanced by applying more negative bias (InHCF vs. PANI). When the coloring voltage attained -1.1 or $-1.2 \mathrm{~V}$, the transmittance attenuation $(\Delta T)$ increased to ca. $60 \%$. By contrast, the $\Delta T$ values were only ca. $30 \%$ and $50 \%$ for -0.8 and $-1.0 \mathrm{~V}$, respectively. When the coloring potential reached $-1.3 \mathrm{~V}$ (see Fig. 8(e)), the optical performance of the device decayed rapidly after 70 cycles. This might imply the occurrence of less reversible redox reactions of PANI, as mentioned earlier (Eqs. (2) and (3)). The degradation of the ECD performance became more obvious when a coloring voltage of $-1.5 \mathrm{~V}$ was applied. The relevant data is shown in Fig. 8(f). With such a coloring voltage, the ECD could no longer function after 30 cycles. The device data measured under different operating conditions is summarized in Table 1. From the above data, we observed that the optimal coloring voltage for this system is $-1.2 \mathrm{~V}$. Under this condition, the transmittance attenuation can reach $63 \%$ (from $70 \%$ to $7 \%$ ) and very slightly drift to $60 \%$ (from $68 \%$ to $8 \%$ ) after 100-cycle switches.

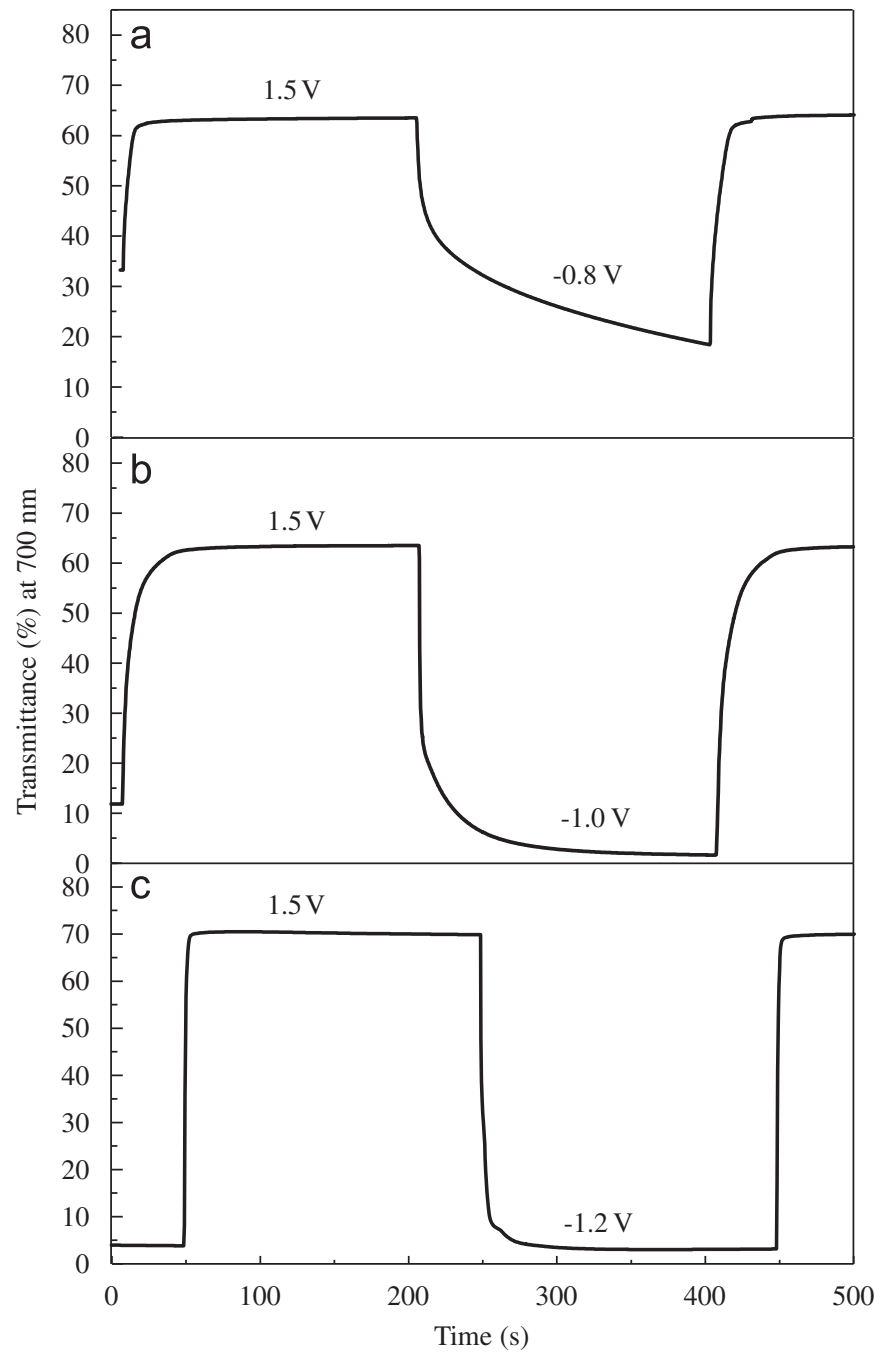

Fig. 7. The transmittance response curves of the PANI/K-PAMPS/ InHCF ECD recorded at different operating voltages: (a) $-0.8-1.5$, (b) $-1.0-1.5$, and (c) $-1.2-1.5 \mathrm{~V}$.

\section{Conclusions}

On the basis of the above findings, the feasibility of a new ECD based on polyelectrochromic PANI, pseudotransparent InHCF, and K-PAMPS gel electrolyte, has been demonstrated. The precoloring-free device could exhibit blue-green-yellowish electrochromism and is reversibly switched between dark green and yellowish states. It was discovered that the coloring voltage significantly influences both the optical performance and the cycling stability of the present system. When the coloring voltage is more positive than $-1.2 \mathrm{~V}$ (InHCF vs. PANI), the device can be colored reversibly for at least 100 cycles. Moreover, the transmittance attenuation $(\Delta T)$ can be greatly enhanced to ca. $60 \%$ from ca. $30 \%$ by applying more negative bias (InHCF vs. PANI). When the device is colored between -1.3 and $-1.5 \mathrm{~V}$, the optical performance and cycling stability will both decay rapidly 
a

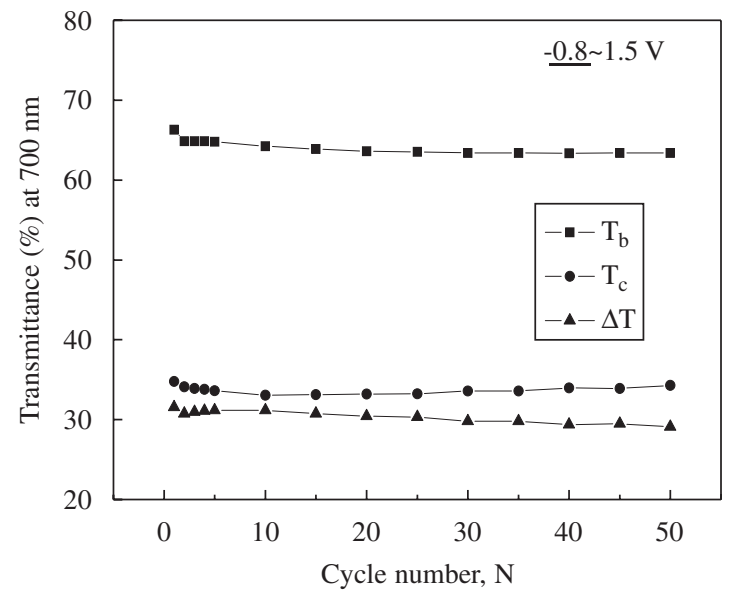

b

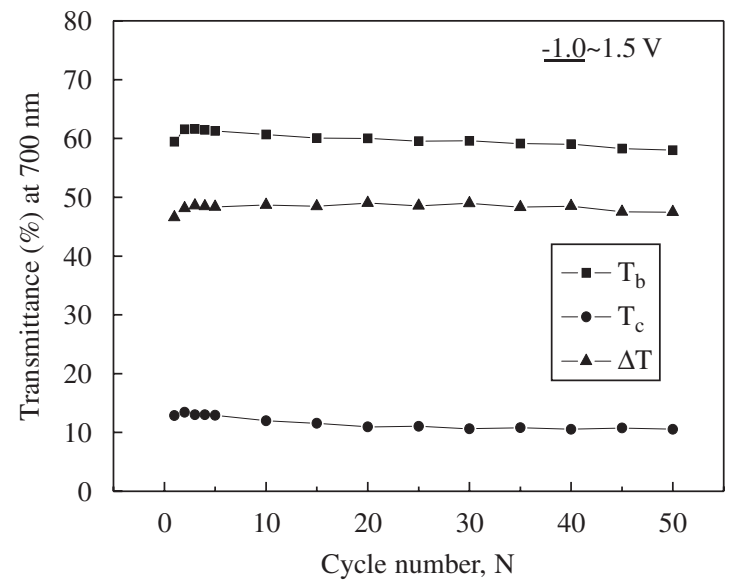

C

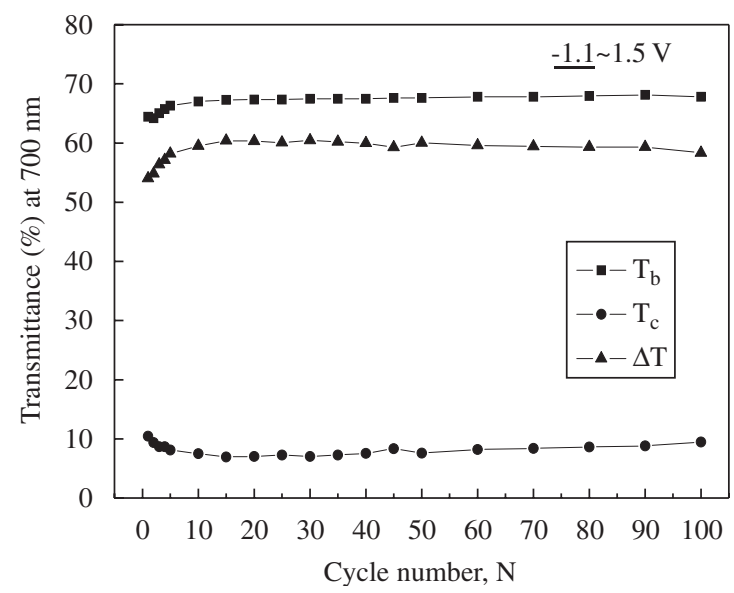

d

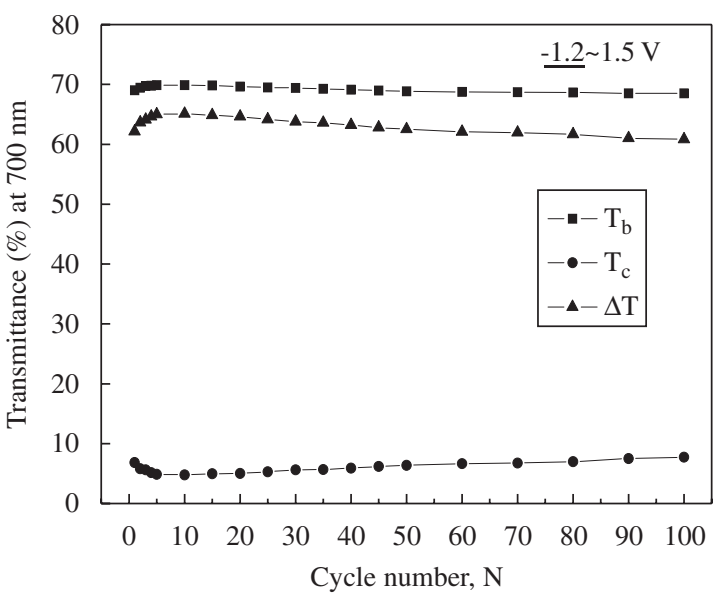

e

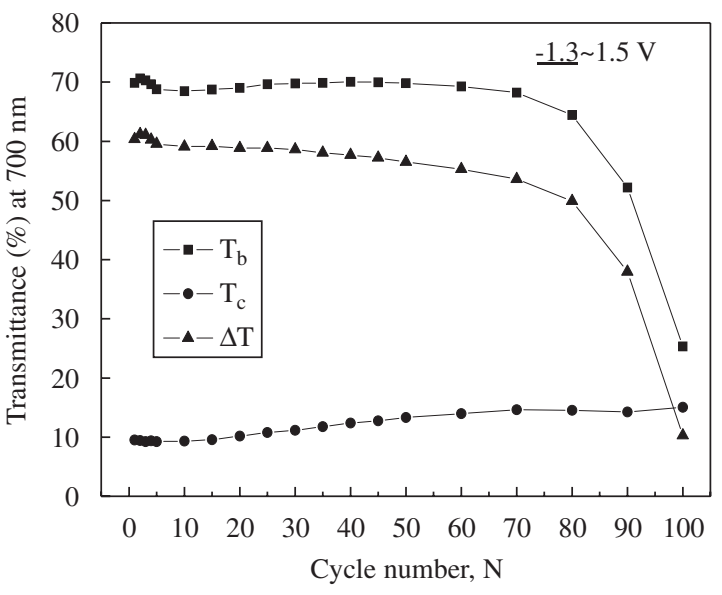

$f$

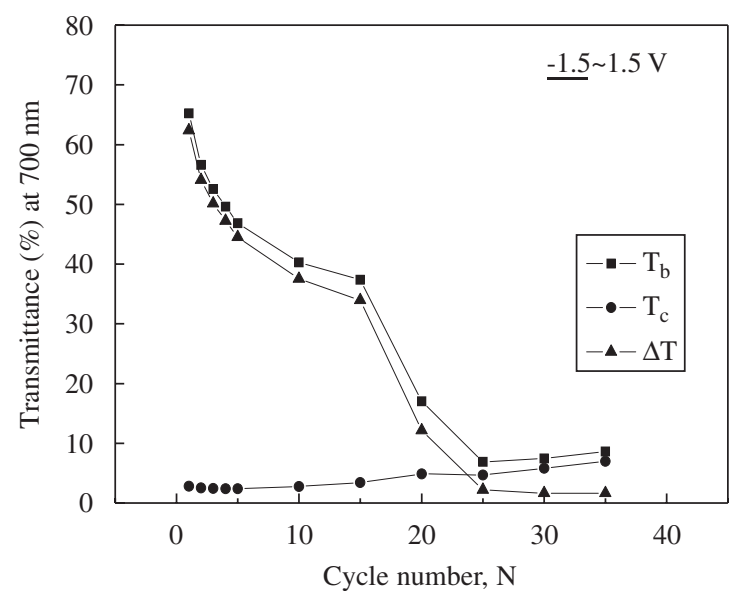

Fig. 8. The transmittance values at bleached state $\left(T_{\mathrm{b}}\right)$, darkened state $\left(T_{\mathrm{d}}\right)$, and the transmittance change $(\Delta T)$ at $700 \mathrm{~nm}$ of PANI/K-PAMPS/InHCF ECDs as a function of cycle number. The devices were operated respectively in the following voltage ranges: (a) $-0.8-1.5$, (b) $-1.0-1.5$, (c) $-1.1-1.5$, (d) $-1.2-1.5$, (e) $-1.3-1.5$, and (f) $-1.5-1.5 \mathrm{~V}$.

and finally quench. Judging from the results of the in situ optoelectrochemical measurement, we conclude that the optimal coloring voltage for the present ECD is $-1.2 \mathrm{~V}$ (InHCF vs. PANI), while the bleaching voltage can be set as $1.5 \mathrm{~V}$. Ideally, the optimization of coloring voltage will prompt further improvement in this new system and thus benefit its future application in electrochromic products. 
Table 1

Summary of optical performance and cycling stability for the PANI/K-PAMPS/InHCF ECD operated at different coloring voltages

\begin{tabular}{llll}
\hline Coloring voltage/bleaching voltage $(V)$ & First cycle $T_{\mathrm{c}} / T_{\mathrm{b}} / \Delta T(\%)$ & 50 th cycle $T_{\mathrm{c}} / T_{\mathrm{b}} / \Delta T(\%)$ & 100 th cycle $T_{\mathrm{c}} / T_{\mathrm{b}} / \Delta T(\%)$ \\
\hline$-0.8 / 1.5$ & $35 / 66 / 31$ & $34 / 63 / 29$ & N/A \\
$-0.9 / 1.5$ & $34 / 64 / 30$ & $31 / 65 / 34$ & N/A \\
$-1.0 / 1.5$ & $13 / 59 / 46$ & $11 / 58 / 47$ & N/A \\
$-1.1 / 1.5$ & $15 / 71 / 56$ & $10 / 71 / 61$ & $11 / 71 / 60$ \\
$-1.2 / 1.5$ & $7 / 70 / 6$ & $6 / 68 / 62$ & $8 / 68 / 60$ \\
$-1.3 / 1.5$ & $9 / 70 / 61$ & $13 / 70 / 57$ & $15 / 22 / 7$ \\
$-1.5 / 1.5$ & $3 / 66 / 63$ & $2 / 7 / 9$ & N/A \\
\hline
\end{tabular}

\section{Acknowledgements}

The authors wish to thank RiTdisplay Corporation (Hsinchu Industrial Park, Taiwan) for providing the conductive ITO glass substrates. This work was sponsored by the National Research Council of the Republic of China (Taiwan) under grant number NSC 96-ET-7-002-008-ET.

\section{References}

[1] R.J. Mortimer, Chem. Soc. Rev. 26 (1997) 147.

[2] P.M.S. Monk, R.J. Mortimer, D.R. Rosseinsky, Electrochromism: Fundamentals and Applications, VCH, Weinheim, Germany, 1995.

[3] T. Kubo, J. Tanimoto, M. Minami, T. Toya, Y. Nishikitani, H. Watanabe, Solid State Ion. 165 (2003) 97.

[4] S.K. Deb, S.H. Lee, C. Edwin Tracy, J. Roland Pitts, B.A. Gregg, H.M. Branz, Electrochim. Acta. 46 (2001) 2125.

[5] T.J. Richardson, Solid State Ion. 165 (2003) 305.

[6] N. Leventis, M. Chen, A.I. Liapis, J.W. Johnson, A. Jain, J. Electrochem. Soc. 145 (1998) L55.
[7] J. Shah, R.M. Brown Jr., Appl. Microbiol. Biotechnol. 66 (2005) 352.

[8] Z. Jin, S. Dong, Electrochim. Acta 35 (1990) 1057.

[9] P.J. Kulesza, M. Faszynska, Electrochim. Acta 34 (1989) 1749.

[10] K.C. Ho, J.C. Chen, J. Electrochem. Soc. 145 (1998) 2334.

[11] E.M. Genies, A. Boyle, M. Lapkowski, C. Tsintavis, Synth. Metals 36 (1990) 139.

[12] P. Somani, A.B. Mandale, S. Radhakrishnan, Acta Material. 48 (2000) 2859.

[13] J. Desilvestro, W. Scheifele, O. Hass, J. Electrochem. Soc. 142 (1995) 2894.

[14] S.K. Dhawan, D. Kumar, M.K. Ram, S. Chandra, D.C. Trivedi, Sensors Actuators 40 (1997) 99.

[15] J.P. Radin, J. Electrochem. Soc. 145 (1982) 1215.

[16] L.C. Chen, Y.H. Huang, K.C. Ho, J. Solid State Electrochem. 7 (2002) 6.

[17] T.S. Tung, L.C. Chen, K.C. Ho, Solid State Ion. 165 (2003) 257.

[18] Y.H. Huang, L.C. Chen, K.C. Ho, Solid State Ion. 165 (2003) 269.

[19] K.C. Ho, L.C. Chen, C.C. Lee, Proc. SPIE 3788 (1999) 120.

[20] R.D. Giglia, US Patent 4, 375, 318, 1983.

[21] E.M. Genies, M. Lapkowski, J.F. Penneau, J. Electroanal. Chem. 249 (1988) 97. 